Annuaire du Collège de France 2017-2018

\title{
Algèbre et géométrie (1956-1994)
}

Jean-Pierre Serre

\section{OpenEdition}

Journals

Édition électronique

URL : https://journals.openedition.org/annuaire-cdf/16094

DOI : 10.4000/annuaire-cdf.16094

ISBN : 978-2-7226-0572-5

ISSN : 2109-9227

Éditeur

Collège de France

Édition imprimée

Date de publication : 30 décembre 2020

Pagination : 646

ISBN : 978-2-7226-0516-9

ISSN : 0069-5580

Référence électronique

Jean-Pierre Serre, «Algèbre et géométrie (1956-1994)», L'annuaire du Collège de France [En ligne], 118 | 2020, mis en ligne le 01 avril 2021, consulté le 22 août 2022. URL : http://journals.openedition.org/ annuaire-cdf/16094; DOI : https://doi.org/10.4000/annuaire-cdf.16094 


\title{
ALGĖBRE ET GÉOMÉTRIE (1956-1994)
}

\author{
Jean-Pierre SERRE \\ Membre de l'Institut (Académie des sciences), professeur émérite
}

\section{RECHERCHE (EXPOSÉS)}

Some simple facts about lattices and orthogonal group representations, Harvard, mai 2017 ; EPFL, Lausanne, octobre 2017.

Distribution asymptotique des valeurs propres des endomorphismes de Frobenius (d'après Abel, Chebyshev, Robinson...), sém. Bourbaki, mars 2018.

Weyl groups: involutions and mod 2 cohomology, EPFL, Lausanne, avril 2019.

\section{PUBLICATIONS}

SERRE J.-P., On the mod $\mathrm{p}$ reduction of orthogonal representations, in V.G. KAC et V.L. POPOV (dir.), Lie groups, geometry, and representations theory. A tribute to the life and work of Bertram Kostant, Birkhäuser, 2018, p. 527-540.

SERRE J.-P., Cohomological invariants mod 2 of Weyl groups, Oberwolfach Reports, 2018. 